\title{
FLIP is Constitutively Hyperexpressed in Fas-resistant U266 Myeloma Cells, but Is Not Induced by IL- 6 in Fas-sensitive RPMI8226 Cells
}

\author{
Do Kyun Kim, Eun Sook Cho, Joo-Heon Yoon ${ }^{1,2}$, and Hong-Duck Um ${ }^{2}$ * \\ Laboratory of Cell Biology, Yonsei Medical Research Center, Yonsei University College of Medicine, Seoul 120-752, Korea; \\ ${ }^{1}$ Department of Otorhinolaryngology, Yonsei University College of Medicine, Seoul 120-752, Korea; \\ ${ }^{2}$ Brain Korea 21 Center for Medical Sciences, Yonsei University College of Medicine, Seoul 120-752, Korea.
}

(Received on June 5, 2000)

Despite the expression of Fas, some clones of myeloma cells are resistant to Fas-mediated apoptosis. To define a cellular factor involved in the resistance, we performed a comparative study using two clones of myeloma cells, RPMI8226 and U266. These cells were reported to express cell surface Fas at similar levels, but only RPMI8226 cells lost their viability upon anti-Fas treatment. The resistance of $\mathrm{U} 266$ cells to anti-Fas did not appear to reflect dysregulation of $\mathrm{Bcl}-2, \mathrm{Bcl}-\mathrm{X}_{\mathrm{L}}$, and $\mathrm{Bax}$, because these proteins were expressed in both RPMI8226 and U266 cells to similar levels. Moreover, levels of those proteins were not significantly altered by treating RPMI8226 cells with IL-6, a cytokine which suppresses the Fas-mediated death of RPMI8226 cells. Interestingly, mRNA levels of FLIP $_{L}$, an endogenous inhibitor of Fas signaling, were constitutively elevated in U266 cells. Consistent with this observation, U266 cells expressed both FLIP $_{\mathrm{L}}$ protein and its truncated $43 \mathrm{kDa}$ product which is seen in FLIP $_{L}$-overexpressing cells. The truncated form of FLIP $_{L}$ protein was not detected in RPMI8226. Moreover, the levels of truncated FLIP $_{L}$ in U266 cells were considerably higher than those of pro-FLIP $_{L}$ in RPMI8226. The overall data indicate that FLIP $_{\mathrm{L}}$ is constitutively hyperexpressed in U266 cells. However, IL-6 failed to enhance the protein levels of FLIP molecules in either of the tested cells. It appears, therefore, that FLIP $_{L}$ plays a role in the intrinsic resistance of $\mathrm{U} 266$ cells to the apoptotic action of Fas, but is not involved in the protective action of IL-6.

Keywords: Apoptosis; Fas; FLIP; IL-6; Myeloma Cells.

\footnotetext{
* To whom correspondence should be addressed.

Tel: 82-2-361-8372; Fax: 82-2-362-8647

E-mail: hdum@yumc.yonsei.ac.kr
}

\section{Introduction}

Multiple myeloma is a B cell malignancy resulting from the uncontrolled expansion of a single clone of plasma cells (myeloma cells) in the bone marrow. Although this outgrowth of neoplastic clones reflects either their enhanced capacity to proliferate or a decreased rate of cell death (apoptosis), this latter mechanism may be particularly important in slowly proliferating tumors such as multiple myeloma. Indeed, many, but not all, clones of myeloma cells can withstand a lethal stimulus such as an agonistic anti-Fas antibody (anti-Fas) (Shima et al., 1995; 1996; Westendorf, et al., 1995). Moreover, when the cells are exposed to IL-6, the Fasmediated death of other susceptible clones is suppressed (Chauhan et al., 1997; Shima et al., 1995; Xu et al., 1998). To date, however, the mechanisms underlying the intrinsic and IL-6-induced ability of myeloma cells to survive against anti-Fas have been poorly described.

Fas (APO-1/CD95) is a member of the TNF/nerve growth factor receptor family, and is expressed in a wide variety of normal and transformed cells (Itoh et al., 1991). Upon binding to its ligand, Fas rapidly undergoes oligomerization, followed by recruitment of an adaptor molecule FADD/MORT1 to the ligated receptor (Chinnaiyan et al., 1996). FADD, in turn, associates with caspase-8 (FLICE/MACH/MCH5) through death effector domains (DEDs) present at the C-terminus of FADD and the N-terminus of caspase- 8 , forming the death-inducing signaling complex (DISC) (Boldin et al., 1996). Recruitment of caspase- 8 to the DISC leads to its proteolytic activation, which then triggers a downstream signaling cascade that culminates in apoptosis (Ashkennazi and Dixit, 1998).

FLIP (FLAME-1/MRIT/CLARP) is a recently identified cellular protein which can interfere with the 
Fas-induced activation of caspase-8 (Irmler et al., 1997; Srinivasula et al., 1997). Human cells express two alternatively spliced isoforms of FLIP, FLIP $(28 \mathrm{kDa})$ and FLIP $_{\mathrm{L}}(55 \mathrm{kDa})$ (Irmler et al., 1997). They both contain two DEDs, which are, in the case of FLIP $\mathrm{L}_{\text {, }}$ followed by a caspase-like domain at the C-terminus. Nevertheless, FLIP L $_{\mathrm{L}}$ is believed to be catalytically inactive because the active-center cysteine residue is substituted by a tyrosine residue. FLIP and FLIP $_{\mathrm{L}}$ can interact with FADD and caspase- 8 through DEDs, resulting in blockage of the caspase- 8 activation at the DISC. Consequently, cells stably overexpressing FLIP molecules have been shown to resist Fas-mediated apoptosis (Scaffidi et al., 1999).

Based on the inhibitory role of FLIP, it seems possible that the cellular level of FLIP may be a factor influencing the susceptibility/resistance of myeloma cells to Fas-mediated apoptosis. To address this question, we performed a comparative study using two clones of myeloma cells, RPMI8226 and U266, which have been shown to express Fas to similar levels (Shima et al., 1996). In contrast to RPMI 8226 which undergoes death upon Fas ligation (Shima et al., 1995), U266 cells are resistant to anti-Fas treatment. Interestingly, the FLIP $_{\mathrm{L}}$ protein was found to be hyperexpressed in U266 cells. However, IL-6 failed to elevate the protein levels of either FLIP $_{\mathrm{L}}$ or FLIP $_{\mathrm{s}}$ in RPMI8226 cells. Therefore, FLIP $_{L}$ appears to play a role in the intrinsic resistance of U266 cells to Fas-mediated apoptosis, but does not appear to be involved in the protective action of IL-6.

\section{Materials and Methods}

Materials The culture medium and its supplements were purchased from Bio Whittaker (Walkersville, MD). All the antibodies were raised against human proteins, and were purchased from the following sources; anti-FLIP and -Bax, Pharmingen (San Diego, CA); anti-Bcl-2, DAKO (Carpinteria, CA); anti-Bcl- $\mathrm{X}_{\mathrm{L}}$, Transduction Laboratories (Lexington, KY); anti-Fas (IgM), Upstate Biotechnology (Lake Placid, NY). Promega (Madison, WI) provided deoxynucleotide triphosphate (dNTP), RNasin, avian myeloblastosis virus reverse transcriptase, and random hexamer.

Cell culture and treatments RPMI 8226 and U266 cells were cultured in RPMI1640 medium supplemented with 10\% heatinactivated FBS and gentamicin $(50 \mu \mathrm{g} / \mathrm{ml})$. To treat cells with anti-Fas and IL-6, the cell density was adjusted to $3 \times 10^{5} / \mathrm{ml}$. The untreated control and treated cells were maintained at $37^{\circ} \mathrm{C}$ in $5 \% \mathrm{CO}_{2}$ and high humidity for the periods of time indicated.

Analysis of viability Incubated cells received propidum iodide (PI) $(5 \mu \mathrm{g} / \mathrm{ml})$, followed by analysis on a FACScan flow cytometer (Becton Dichinson, Mountain View, CA) to simultaneously monitor PI uptake (FL-2 channel) and cell size (forward light scatter). The cells that displayed both a reduction in cell size and a high permeability to PI were understood to be dead, as previously defined (Mangan et al., 1991).

Western blotting Cell lysates were prepared as described previously (Lee and Um, 1999). Equal amounts of proteins $(25-100 \mu \mathrm{g})$ were separated by SDS-PAGE, then electrotransferred to Immobilon membranes (Millipore, Bedford, MA) which were subsequently blotted using the indicated antibodies and visualized by chemiluminescence (ECL; Amersham, Arlington Heights, IL).

RT-PCR analysis Total RNA from indicated cells was extracted using Tri-reagent (Sigma, St. Louis, MO). Firststrand cDNA was synthesized at $37^{\circ} \mathrm{C}$ for $1 \mathrm{~h}$ in $50 \mu \mathrm{l}$ of reaction mixture containing $3 \mu \mathrm{g}$ of total RNA, $1.5 \mathrm{mM}$ of each dNTP, $0.5 \mu \mathrm{g}$ of random hexamer, 10 units of avian myeloblastosis virus reverse transcriptase, and 25 units of RNasin. PCR reactions were then performed in a total volume of $25 \mu \mathrm{l}$ containing $5 \mu \mathrm{l}$ of the transcribed cDNA, 1 unit of Taq DNA polymerase (Takara, Shiga, Japan), $0.2 \mu \mathrm{M}$ of each dNTP, $0.5 \mu \mathrm{Ci}$ of $\left[\alpha^{32} \mathrm{P}\right]-\mathrm{CTP}$, and 25 pmole of each primer. Two sets of primers were used for the amplification of FLIP cDNA; one (5'-ATG TCT GCT GAA GTC ATC CAT C-3', and $5^{\prime}$-TGC TCC TTG AAC AGA CTG C-3') specific to the $\mathrm{N}$-terminal region of FLIP which is commonly shared by FLIP $_{\mathrm{L}}$ and FLIP $_{\mathrm{S}}$, and the other (5'-TCA GAG CAT ACC TGA AGA G-3', and 5'-AGA GTG TGC TGC AGC CAG AC-3') specific to the C-terminal extension of FLIP $_{L}$. For an internal control, $\beta$-actin cDNA was amplified by using 5'-GTG GGG CGC CCC AGG CAC CA-3' and 5'-TCC TTA ATG TCA CGC ACG ATT TC-3'. The optimal number of cycles for RT-PCR was determined as previously described (Becker et al., 1991), and we performed the amplification at 23 cycles for $\beta$-actin, at 25 cycles for the shared $\mathrm{N}$-terminal region of FLIP, and at 27 cycles for the C-terminal extension of $\mathrm{FLIP}_{\mathrm{L}}$. Each cycle included denaturation at $94^{\circ} \mathrm{C}$ for $30 \mathrm{~s}$, primer annealing at $60^{\circ} \mathrm{C}$ for $30 \mathrm{~s}$, and extension at $72^{\circ} \mathrm{C}$ for $1 \mathrm{~min}$. Ten $\mu \mathrm{l}$ of the reaction mixture was separated on $5 \%$ acrylamide gels, and the relative levels of amplification were compared by autoradiography of the gels.

\section{Results}

Anti-Fas kills RPMI8226, but not U266 myeloma cells RPMI8226 myeloma cells express Fas on their surface, and thus undergo death upon exposure to antiFas (Shima et al., 1995). The cell death was suppressed by the addition of IL-6 (Fig. 1), as reported previously (Shima et al., 1995). It has also been reported that U266 clones of myeloma cells express cell surface Fas to a level similar to that observed in RPMI8226 cells (Shima et al., 1996). However, U266 cells resisted the anti-Fas treatment even in the absence of exogenous IL-6 (Fig. 1). These data suggested that U266 cells constitutively express an anti-death protein(s) which blocks the Fas signaling.

Bcl-2, Bcl- $X_{\mathrm{L}}$, and Bax are not hyperexpressed in U266 cells Bcl-2 and $\mathrm{Bcl}-\mathrm{X}_{\mathrm{L}}$ are well characterized anti-death 
proteins. Given that overexpression of either $\mathrm{Bcl}-2$ or Bcl- $\mathrm{X}_{\mathrm{L}}$ can suppress Fas-mediated apoptosis (Scaffidi et al., 1998), we explored whether these protective proteins were hyperexpressed in U266 cells. However, levels of Bcl-2 and Bcl- $\mathrm{X}_{\mathrm{L}}$ in U266 cells were not higher than those in RPMI8226 (Fig. 2). It has been proposed that cellular viability can be determined by the ratio of Bcl-2/Bax (Oltvai et al., 1993). However, both RPMI8226 and U266 cells expressed Bax to similar levels. It appeared, therefore, that the resistance of U266 cells to anti-Fas did not result from dysregulation of the tested members of the Bcl-2 family. Moreover, the exposure of either RPMI8226 or U266 cells to IL-6 did not significantly alter their levels of Bcl-2, Bcl- $\mathrm{X}_{\mathrm{L}}$, and Bax.

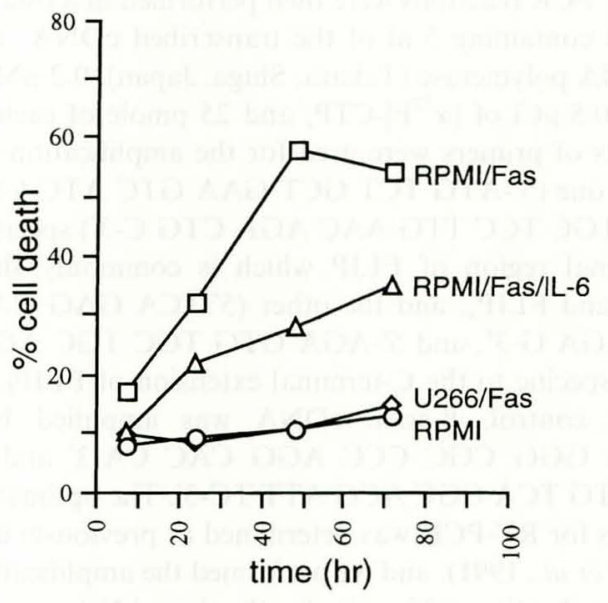

Fig. 1. Differential responses of RPMI8226 and U266 cells to anti-Fas. RPMI8226 and U266 cells were incubated in the following conditions: circle, RPMI8226 in the absence of antiFas and IL-6; square, RPMI8226 in the presence of anti-Fas $(0.1 \mu \mathrm{g} / \mathrm{ml})$; triangle, RPMI8226 in the presence of both anti-Fas and IL-6 (1,000 U/ml); diamond, U266 in the presence of antiFas. Following the incubation times indicated, cellular viability was determined by flow cytometric analysis. The data is representative of three similar experiments. The viability of untreated U266 cells was almost equal to those treated with anti-Fas.

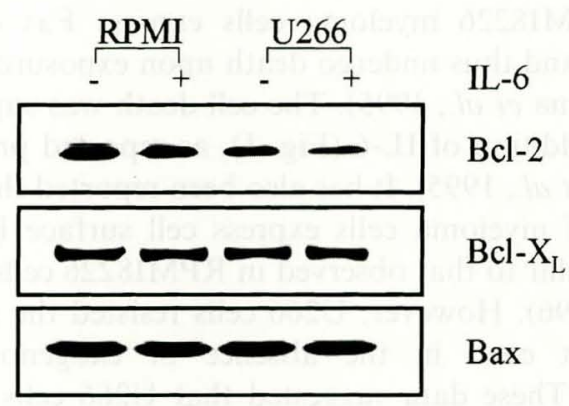

Fig. 2. Expression of $\mathrm{Bcl}-2, \mathrm{Bcl}-\mathrm{X}_{\mathrm{L}}$, and Bax. RPMI8226 and U266 cells were incubated in the absence or presence of IL-6 $(1,000 \mathrm{U} / \mathrm{ml})$ for $24 \mathrm{~h}$. Levels of $\mathrm{Bcl}-2, \mathrm{Bcl}-\mathrm{X}_{\mathrm{L}}$, and Bax were compared by Western blotting as described in Materials and Methods.
FLIP is hyperexpressed in U266 cells Based on the report that Fas-mediated apoptosis is blocked by overexpression of FLIP (Irmler et al., 1997; Scaffidi et al, 1999; Srinivasula et al., 1997), we next compared the levels of FLIP molecules in RPMI8226 and U266 cells. To do so, RT-PCR was conducted by using a set of primers that was specific to the $\mathrm{N}$-terminal region of

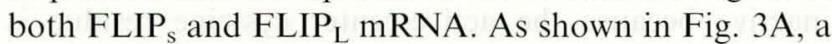
greater amplification was obtained using cDNA from U266 cells, suggesting higher levels of FLIP mRNAs in the cells. Similar results were obtained using the other set of primers that was specific to the $\mathrm{C}$-terminal extension of FLIP $_{L}$ mRNA. Therefore, the FLIP mRNAs which were up-regulated in U266 cells involved FLIP $_{L}$ mRNA. When levels of FLIP proteins were compared by Western analysis, we did not detect the $28 \mathrm{kDa}$ FLIP $_{\mathrm{s}}$ protein in either of the cells (Fig. 3B). While the two cells expressed the $55 \mathrm{kDa}$ FLIP $_{\mathrm{L}}$ protein, the $\mathrm{U} 266$ cells displayed an additional protein band corresponding to $43 \mathrm{kDa}$. This protein represents the proteolytically truncated form of $\mathrm{FLIP}_{\mathrm{L}}$ protein, which has been commonly observed in cells overexpressing FLIP $_{\mathrm{L}}$ (Irmler et al., 1997; Scaffifi et al., 1999). Importantly, the levels of the $43 \mathrm{kDa}$ form in U266 cells were much higher than those of the $55 \mathrm{kDa}$ form in RPMI8226 cells. These data suggested that expression of the FLIP $\mathrm{L}_{\mathrm{L}}$ protein was enhanced in U266 cells to the

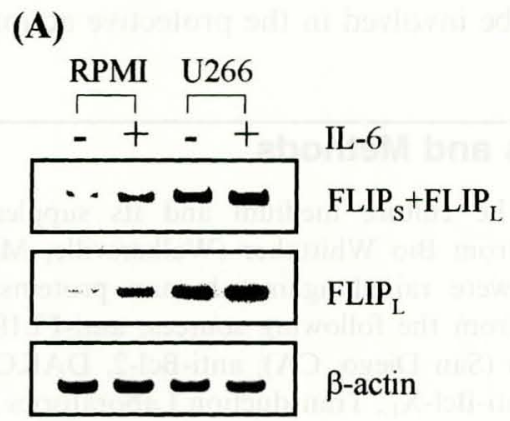

(B)

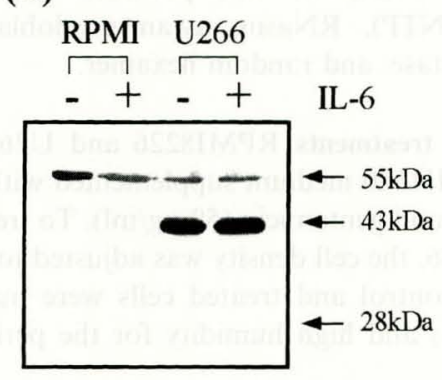

Fig. 3. Expression of FLIP mRNA and proteins. RPMI8226 and U266 were incubated in the absence or presence of IL-6 $(1,000 \mathrm{U} / \mathrm{ml})$. A. At $8 \mathrm{~h}$ after the treatment, total RNA was extracted, and the levels of FLIP mRNA were compared by RTPCR. B. After $24 \mathrm{~h}$, the levels of FLIP proteins were analyzed by Western Blotting. 
level that the protein could undergo its proteolytic cleavage.

IL-6 induces FLIP mRNA, but not its protein, in RPMI8226 cells To explore whether the protective effect of IL-6 is accompanied by the induction of FLIP, we treated RPMI8226 cells with IL-6 for $8 \mathrm{~h}$, and analyzed the levels of FLIP mRNA. As shown in Fig. 3A, IL-6 dramatically enhanced the levels of FLIP mRNA. This effect of IL- 6 was observed using both sets of primers. However, IL-6 did not significantly influence the level of the $55 \mathrm{kDa}$ FLIP $_{\mathrm{L}}$ protein (Fig. 3B). Moreover, we did not detect any induction of the $28 \mathrm{kDa}$ FLIP $_{\mathrm{s}}$ protein and the truncated form of FLIP $_{\mathrm{L}}$ by treating RPMI8226 cells with IL-6. This was true when we analyzed the FLIP proteins from $4 \mathrm{~h}$ up to $48 \mathrm{~h}$ after the treatment. These results indicated that levels of FLIP mRNA, but not its protein, are under the control of IL-6 in RPMI8226 cells.

In the case of U266, levels of FLIP mRNA did not significantly respond to IL-6 (Fig. 3A), suggesting that FLIP mRNA was in a saturated level without the IL-6 treatment. Similarly, the levels and expression patterns of FLIP proteins were not altered by treating U266 cells with IL-6 (Fig. 3B).

\section{Discussion}

Recent studies have demonstrated that certain clones of myeloma cells resist Fas-mediated apoptosis (Shima et al., 1995; 1996; Westendorf, et al., 1995). To determine the cellular factor involved in the resistance, we have performed a comparative study using RPMI 8226 and U266 myeloma cells. Although these two cells express Fas to similar levels (Shima et al. 1996), only RPMI8226, but not U266, cells were susceptible to the lethality by anti-Fas. It appears that $\mathrm{Bcl}-2$ and $\mathrm{Bcl}-\mathrm{X}_{\mathrm{L}}$ are not the constitutive protectors of $\mathrm{U} 266$ cells, because levels of those proteins were not enhanced in U266 cells, compared to RPMI8226. Similarly, studies using different sets of myeloma cells have reported that cellular levels of $\mathrm{Bcl}-2$ and $\mathrm{Bcl}-\mathrm{X}_{\mathrm{L}}$ are not co-related to the responsiveness of myleoma cells to anti-Fas (Egle et al., 1997). Although it has been proposed that the cellular level of Bax is a factor determining the susceptibility of certain clones of myeloma cells to anti-Fas (Egle et al., 1997), we could not find such a co-relation using RPMI8226 and U266 cells. Therefore, the resistance to anti-Fas appears to be achieved by different mechanisms depending on myeloma cell clones. In the case of U266 cells, we observed up-regulation of FLIP $_{L}$ mRNA and its truncated form of protein. Although we could not detect the FLIP protein in the tested myeloma cells, this does not necessarily indicate that the cells do not express the FLIP $\mathrm{s}_{\mathrm{s}}$ mRNA. This argument is based on the observation that human peripheral blood $\mathrm{T}$ cells highly express FLIP $_{\mathrm{s}}$ mRNA, but not its protein (Irmler et al., 1997). Therefore, transcription of FLIP does not seem to always guarantee its translation, suggesting a control at the level of post-transcription. Although high levels of FLIP $_{\mathrm{L}}$ protein were detected in malignant melanoma cells (Irmler et al., 1997), this is, to our knowledge, the first report that FLIP can be dysregulated in myeloma cells. The role of FLIP in apoptosis was initially controversial: overexpression of FLIP resulted in either suppression or promotion of Fasmediated cell death depending on experimental conditions (Han et al., 1997; Inohara et al., 1997; Irmler et al., 1997; Srinivasula et al., 1997). It was later proposed that the promotion of cell death reflects the non-physiological function of FLIP in transient overexpression systems, and that its stable hypexpression is antiapoptotic (Scaffidi et al., 1999). Moreover, overexpression of $\mathrm{FLIP}_{\mathrm{L}}$ was shown to elicit a more potent protective effect than that of $\mathrm{FLIP}_{\mathrm{S}}$ (Irmler et al., 1997). Interestingly, when FLIP $_{\mathrm{L}}$ was overexpressed in $\mathrm{BJAB}$ lymphoma cells, only the $43 \mathrm{kDa}$, but not the $55 \mathrm{kDa}$, form of FLIP $_{\mathrm{L}}$ was detected in the DISC (Scaffifi et al., 1999). This suggests that the $43 \mathrm{kDa}$ form of $\mathrm{FLIP}_{\mathrm{L}}$ participates in the blockage of Fas signaling. In this regard, the constitutive hyperexpression of the $43 \mathrm{kDa}$ FLIP protein in U266 cells is consistent with the intrinsic ability of the cells to survive against anti-Fas.

Another important finding of this study is that IL-6 does not regulate the levels of FLIP proteins in the tested myeloma cells. Although levels of FLIP $_{\mathrm{L}}$ mRNA in RPMI8226 cells were enhanced by IL-6, this effect was not reflected in its protein level. This suggests that the expression of FLIP ${ }_{\mathrm{L}}$, like FLIP , can also be under post-transcriptional control. Certain cytokines such as $\mathrm{TNF} \alpha$ and IFN $\gamma$ were shown to elevate the mRNA levels of FLIP in microglial cells (Spanaus et al., 1998). Based on our finding that the levels of FLIP mRNA and its protein can be differentially regulated, FLIP should be analyzed at its protein level as well to confirm the action of the cytokines. We have also investigated the possibility that IL- 6 could regulate cellular levels of $\mathrm{Bcl}-2, \mathrm{Bcl}-\mathrm{X}_{\mathrm{L}}$, and Bax. However, we could not find evidence for this under our experimental conditions. Taken together, the data indicate that IL- 6 can suppress the Fas-mediated death of RPMI8226 cells without altering the levels of FLIP proteins and the tested members of the Bcl-2 family. Currently, the mechanism underlying the protective action of IL-6 is unclear. While IL-6 has been reported to suppress the Fasmediated activation of stress-activated protein kinase/ c-Jun N-terminal kinase (SAPK/JNK) (Chauhan et al., 1997; Xu et al., 1998), whether SAPK acts as a mediator of Fas-induced death in myeloma cells remains unanswered. Such a verification appears to be important because the role of SAPK in Fas-mediated apoptosis 
varies depending on the cell type (Ashkenazi and Dixit, 1998).

In summary, we have provided evidence that FLIP is dysregulated in Fas-resistant U266 myeloma cells. Therefore, FLIP may be considered as a survival factor imparting at least those specific cells with an intrinsic resistance to lethality by Fas ligation. Given that IL-6 rescues Fas-sensitive RPMI8226 myeloma cells without altering their levels of FLIP proteins, myeloma cells appear to have an alternative control for their response to the Fas ligand.

Acknowledgements This work was supported by the Cancer Control Program (1997-1998) from the Ministry of Health and Welfare, Korea. The authors thank Dr. Won-Jae Lee for his technical advice.

\section{References}

Ashkenazi, A. and Dixit, V. M. (1998) Death receptors; signaling and modulation. Science 281, 1305-1308.

Becker, S., Quay, J., and Soukup, J. (1991) Cytokine (tumor necrosis factor, IL-6, and IL-8) production by respiratory syncytial virus-infected human alveolar macrophages. J. Immunol. 147, 4307-4312.

Boldin, M. P., Goncharov, T. M., Goltsev, Y. V., and Wallach, D. (1996) Involvement of $\mathrm{MACH}$, a novel MORT1/FADD-interacting protease, in Fas/APO-1- and TNF receptor-induced cell death. Cell $\mathbf{8 5}, 803-815$.

Chauhan, D., Kharbanda, S., Ogata, A., Urashima, M., Teoh, G., Robertson, M., Kufe, D. W., and Anderson, K. C. (1997) Interleukin-6 inhibits Fas-induced apoptosis and stress-activated protein kinase activation in multiple myeloma cells. Blood 89, 227-234.

Chinnaiyan, A. M., Tepper, C. G., Seldin, M. F., O'Rourke, K., Kischkel, F. C., Hellbardt, S., Krammer, P. H., Peter, M. E., and Dixit, V. M. (1996) FADD/MORT1 is a common mediator of CD95 (Fas/APO-1) and tumor necrosis factor receptor-induced apoptosis. J. Biol. Chem. 271, 4961-4965.

Egle, A., Villunger, A., Marschitz, I., Kos, M., Hittmair, A., Lukas, P., Grunewald, K., and Greil, R. (1997) Expression of APO-1/Fas (CD95), Bcl-2, Bax and $\mathrm{Bcl}_{-} \mathrm{X}_{\mathrm{L}}$ in myeloma cell lines: relationship between responsiveness to anti-Fas mab and p53 functional status. Br. J. Haematol. 97, 418-428.

Han, D. K. M., Chaudhary, P. M., Wright, M. E., Friedman, C., Trask, B. J., Riedel, R. T., Baskin, D. G., Schwartz, S. M., and Hood, L. (1997) MRIT, a novel death effector domaincontaining protein, interacts with caspases and $\mathrm{Bcl}-\mathrm{X}_{\mathrm{L}}$ and initiates cell death. Proc. Natl. Acad. Sci. USA 94, $11333-11338$.

Inohara, N., Koseki, T., Hu, Y., Chen, S., and Nunez, G. (1997) CLARP, a death effector domain-containing protein interacts with caspase- 8 and regulates apoptosis. Proc. Natl. Acad. Sci. USA 94, 10717-10722.
Irmler, M., Thome, M., Hahne, M., Schneider, P., Hofmann, K., Steiner, V., Bodmer, J. -L., Schroter, M., Burns, K., Mattmann, C., Rimoldi, D., French, L. E., and Tschopp, J. (1997) Inhibition of death receptor signals by cellular FLIP. Nature 388, 190-195.

Itoh, N., Yonehara, S., Ishii, A., Yonehara, M., Mizushima, S. -I., Sameshima, M., Hase, A., Seto, Y., and Nagata, S. (1991) The polypeptide encoded by the cDNA for human cell surface antigen Fas can mediate apoptosis. Cell $\mathbf{6 6}$, 233-243.

Lee, B. R. and Um, H. -D. (1999) Hydrogen peroxide suppresses U937 cell death by two different mechanisms depending on its concentration. Exp. Cell Res. 248, 430 438.

Mangan, D., Welch, G. R., and Wahl, S. M. (1991) Lipopolysaccharide, tomuor necrosis factor $\alpha$, and IL-1 $\beta$ prevent programmed cell death (apoptosis) in human peripheral blood monocytes. J. Immunol. 146, 1541-1546.

Oltvai, Z. N., Milliman, C. L., and Korsmeyer, S. J. (1993) $\mathrm{Bcl}-2$ heterodimerizes in vivo with a conserved homolog, Bax, that accelerates programmed cell death. Cell 74, 609619.

Scaffidi, C., Fulda, S., Srinivasan, A., Friesen, C., Li, F., Tomaselli, K. J., Debatin, K. -M., Krammer, P. H., and Peter, M. E. (1998) Two CD95 (APO-1/Fas) signaling pathways. EMBO J. 17, 1675-1687.

Scaffidi, C., Schmitz, I., Krammer, P. H., and Peter, M. E. (1999) The role of c-FLIP in modulation of CD95-induced apoptosis. J. Biol. Chem. 274, 1541-1548.

Shima, Y., Nishimoto, N., Ogata, A., Fujii, Y., Yoshizaki, K., and Kishimoto, T. (1995) Myeloma cells express Fas antigen/APO-1 (CD95) but only some are sensitive to anti-Fas antibody resulting in apoptosis. Blood 85, 757764.

Shima, Y., Nishimoto, N., Yoshizaki, K., and Kishimoto, T. (1996) Fas antigen/APO-1 (CD95) expression on myeloma cells. Leukemia Lymphoma 23, 521-531.

Spanaus, K. S., Schlapbach, R., and Fontana, A. (1998) $\mathrm{TNF} \alpha$ and IFN $\gamma$ render microglia sensitive to Fas ligandinduced aoptosis by induction of Fas expression and downregulation of Bcl-2 and Bcl-X $\mathrm{L}_{\mathrm{L}}$. Eur. J. Immunol. 28, 43984408 .

Srinivasula, S. M., Ahmad, M., Ottilie, S., Bullrich, F., Bamks, S., Wang, Y., Fernandes-Alnemri, T., Croce, C. M., Litwack, G., Tomaselli, K. J., Armstrong, R. C., and Alnemri, E. S. (1997) FLAME-1, a novel FADD-like antiapoptotic molecule that regulates Fas/TNFR1-induced apoptosis. J. Biol. Chem. 272, 18542-18545.

Westendorf, J. J., Lammert, J. M., and Jelinek, D. F. (1995) Expression and function of Fas (APO-1/CD95) in patient myeloma cells and myeloma cell lines. Blood 85, 35663576.

Xu, F. -H., Sharma, S., Gardner, A., Tu, Y., Raitano, A., Sawyers, C., and Linchtenstein, A. (1998) Interleukin-6induced inhibition of multiple myeloma cell apoptosis: support for the hypothesis that protection is mediated via inhibition of the JNK/SAPK pathway. Blood 92, 241251. 